\title{
Where have you Gone, Sherlock Holmes?
}

\section{John Fremont Fisher,*}

Professor of Medicine, Georgia Regents University, Augusta, GA, USA

\begin{abstract}
Dr. Jack House is a fictitious infectious disease fellow who has been allowed to practice superficial and potentially harmful patient evaluations because attending physicians are too busy to adequately supervise him. His consultations on four critically ill patients have been performed in haste and recommendations have been based on faulty reasoning with inadequate data. He has failed to incorporate microscopy into his thought process and his clinical notes are overly brief, poorly written, and call for inappropriately broad-spectrum antimicrobial therapy.

His consultation style is contrasted with real examples of patients who were evaluated by an infectious disease consultant who relied heavily on clinical exam and microscopic findings to arrive at an accurate diagnosis and to give recommendations for appropriate antimicrobial therapy. The article is a commentary on an increasingly pervasive type of infectious disease practice.
\end{abstract}

It was November 30th and today his beeper had vibrated so many times that the first signs of a friction burn had developed over the right iliac crest of Jack House MD, first-year ID fellow at Summa Cum Laude University Medical Center. If the beeper had been in his shirt pocket, he might have developed a productive cough. He had already "seen" and scribbled a one-paragraph note on three new consults recommending doripenem plus caspofungin for two of the patients who had some kind of enigmatic, febrile illness. He had successfully fended off six other consults by asking the callers if the patient could be seen tomorrow and whining about being swamped, craftily concealing the fact that another fellow was taking over the service in the AM.

Two of the four patients he reluctantly agreed to evaluate were in the ICU receiving mechanical ventilation. These acutely ill individuals, like many others in his three previous rotations on the consult service, had a tube in every orifice. Both were on contact isolation. Dr. House perfunctorily donned his yellow gown and latex gloves and went into the patients' rooms. He glanced vacantly at their careworn faces and listened with the patients' dedicated stethoscopes through their gowns over the precordial area and the anterior, apical lung regions. Since no attending in his training had ever examined patients in sufficient detail to challenge his physical findings, he had settled in to this exam style with surprisingly little guilt. If pressed, he knew down deep, after these brief patient encounters, he could only honestly certify (1) that the heart and lungs were present and (2) that the patients were on a ventilator even though his note claimed that the lungs were "clear to A \& P." His guilt was assuaged to a large degree because that same abbreviation was common to the notes of the junior medical student, medicine resident, and critical care fellow for the past 48 hours on both patients. The pulmonary attending who was the very soul of brevity had "agreed with house staff's findings and treatment plan" each day.

Dr. House felt comforted by his assumption that the official laboratory and X-ray findings would tell him all he really needed to know about these patients. He hadn't carried an ophthalmoscope since he was a junior medical student (None of the fellows and medicine residents did either.). The thought of getting a nurse to help him turn the patients to listen to the posterior lung fields and examine for a rash and pressure sores or to obtain a suctioned sputum or urine sample for microscopy never even entered his head. Furthermore, he had to get the notes written before rounds if he wanted to get to his lucrative moonlighting job by 5:30PM.
Dr. House made it a practice each day to review the Sanford Guide to Antimicrobial Therapy just before attending rounds relative to all new consults and he did very well on standardized exams. Furthermore, he was "hail 'fellow' well met," had movie-star good looks, and had played middle linebacker for the state university as an undergraduate. As expected, he was very popular with attendings of either gender, but not with the other ID fellows to whom he turned over the service.

His third patient was on 9 West Medical Ward with a refractory community-acquired pneumonia whose sputum had yielded only Candida albicans in culture. In his thinking process, since the Microbiology Laboratory had reported that the sample contained many neutrophils, the yeast must have undoubtedly been real and needed treating. Dr. House reasoned that he should once again recommend doripenem in addition to the echinocandin on the outside chance that the patient's probable Candida pneumonia was part of a polymicrobial infection which included Pseudomonas or anaerobes. Caspofungin was advised because reports are rampant about the increasing resistance of yeast to fluconazole. As far as going to the Microbiology Laboratory to review the Gram's stain from the patient's current sputum sample or original admission sample, forget that. He had never had an ID attending in his first three rotations on the consult service who told him that this exercise might provide useful diagnostic information even if the smear revealed no organisms. He would have been dumfounded if one of his ID attendings had asked him if he had looked at a wet mount, AFB smear, or Wright stain of the sputum samples. However, this wasn't likely since all of his supervisors were under 40 and very busy in their laboratories and he knew they would sign off on his doripenem plus caspofungin cocktail.

*Corresponding author: John Fremont Fisher, MD FACP FIDSA, Professor of Medicine, Georgia Regents University, Augusta, GA, USA, E-mail: JFISHER@gru.edu

Received October 18, 2013; Accepted October 21, 2013; Published October 29 2013

Citation: Fisher JF (2013) Where have you Gone, Sherlock Holmes? Clin Microbial 2: e114. doi: $10.4172 / 2327-5073.1000 \mathrm{e} 114$

Copyright: (C) 2013 Fisher JF. This is an open-access article distributed under the terms of the Creative Commons Attribution License, which permits unrestricted use, distribution, and reproduction in any medium, provided the original author and source are credited. 
For the last consult Dr. House planned to see before attending rounds that day, he recommended six weeks of daptomycin plus rifampin for a patient with a spinal cord injury and, according to the nurse, "a nasty looking, stage-three, sacral pressure sore." Once again he confirmed that this patient's heart and lungs were present, but Dr. House did not take the dressing down from the decubitus ulcer and check with sterile gloves for the presence of exposed bone, undermined wound margins, fascial integrity, and malodorous discharge. However, swabs of the ulcer had yielded VRE and this organism, especially if it involved bone, he felt must be treated for a long time.

His handwriting on the three notes was so scrawled that it took the consulting residents longer to read the note than Dr. House took to evaluate the patients. They were never able to decipher whose signature and beeper number was on the consult form, but fortunately they were able to make out Doribax ${ }^{\circledR}+$ Cancidas $^{\circledR}$, and Cubicin ${ }^{\circledR}$. Dr. House, like all residents and faculty, used trade names because the generic names were just too hard to pronounce. Ironically, Summa Cum Laude University Medical Center was one of the first medical schools to outlaw pharmaceutical representatives on campus. They needn't have. The constant use of these Madison Avenue-conceived proprietary names and many others besides $\left(\right.$ Zosyn $^{\circledR}$, Rocephin ${ }^{\circledR}$, Levaquin $^{\circledR}$, Primaxin ${ }^{\circledR}$, Reyataz $^{\circledR}$, Presista ${ }^{\circledR}$, Valtrex $^{\circledR}$, and Truvada $\left.{ }^{\circledR}\right)$ do the selling in absentia for the reps. The junior medical students were just beginning to master the trade names after five months on the wards and a difficult second year with generics and structureactivity relationships. Most residents and fellows remember what class of antimicrobials these agents belong to, but little else. Dr. House's cramming for a few minutes each day with the Sanford Guide helped him appear to them a walking encyclopedia of antimicrobial therapeutics. Even his ID attendings noted on his evaluations that his fund of knowledge right down to correct dosages of medications for renal insufficiency was precocious for his level of training. No mention was ever made of the clarity or quality of his consult notes.

That Dr. House has no genuine interest in precise infectious disease diagnosis or in-depth understanding and judicious use of antibiotics are symptoms of a poorly encapsulated neoplasm which has metastasized throughout the United States. However, the blame cannot be completely placed on him or our other young trainees. It must be shared. To borrow from Walt Kelly's Pogo, "We have met the enemy and he is us." When we don't inspire our charges to perform careful histories, "world-class" physical examinations, and microscopic analysis of clinical specimens or demonstrate the exhilaration and constant challenge of correctly managing patients with infectious diseases, the fault is ours. We should not only inspire, but expect this pursuit of excellence and trust them to carry it out. That is, trust, but verify.

Needed or not, broad-spectrum antibacterials and antifungals would be effective for most common bacteria and yeast and the fairly frequent clinical improvement of the patients who receive them reinforces their inappropriate use. The physicians who prescribe them are in most instances never challenged on their reasoning for ordering them and rotate off the service or graduate long before the unit has to deal with an outbreak of multi-drug-resistant organisms.

When education committees of our societies can honestly conclude that teaching microscopic skills to ID fellows is not a worthwhile, practical endeavor and is not a part of the Program Requirements of the Accreditation Council on Graduate Medical Education for our specialty, something has gone seriously awry.
Whether or not the Occupational Safety and Health Administration sanctions our interpretation of microscopic smears and wet mounts, we should continue to use these valuable tools to assist us in our decision making. Despite the fact that in many instances microscopy is not helpful and we are forced to employ broad-spectrum agents in critically ill patients, there are frequent occasions when a meticulous exam and the use of the microscope has been pivotal in arriving at a diagnosis and treatment strategy. Here are three examples:

\section{Case 1}

A man with COPD was admitted to the hospital for an acute exacerbation and intubated for respiratory failure. Imaging showed bilateral alveolar infiltrates. Despite broad-spectrum antibiotics, the pneumonia worsened. An infectious disease physician was consulted. Careful physical exam showed diffuse rales in both posterior lung fields. Gram, AFB, and Wright stain of bloody sputum done personally by the consultant disclosed no organisms. Wet mount showed numerous larvae of Strongyloides stercoralis.

\section{Case 2}

A woman in her 20s with advanced AIDS was admitted for high fever and rigors.

A careful system review revealed no pulmonary, urinary tract, or other symptoms.

A thorough physical examination was unhelpful. A complete blood count showed a moderate anemia and thrombocytopenia. Bone marrow aspirate and biopsy was recommended by the ID consultant and performed by the Hematology/Oncology service. Smears and special stains were completed by pathology technicians late in the afternoon and would not be evaluated until the next workday by a pathologist. Because the patient's condition became unstable, hospital security was called to allow access to the Pathology Laboratory after hours. The ID consultant reviewed the Gomori-methenamine silver stain of the bone marrow and found several, small, budding yeast consistent with Histoplasma capsulatum. Amphotericin B was started and by morning the patient was much improved. Bone marrow culture yielded $H$. capsulatum many days later.

\section{Case 3}

The patient was a renal transplant recipient with productive cough and a pulmonary infiltrate unresponsive to broad-spectrum antibiotics. Sputum cultures were pending. The official interpretation of the Gram stain by the Microbiology Laboratory indicated that the sputum was adequate, but no microorganisms were noted. The physicians caring for the patient consulted Infectious Disease. The ID attending reviewed the aforementioned Gram stain and found many examples of faintly staining, beaded, Gram-positive, filamentous rods consistent with Nocardia spp which later grew in culture. The official report was corrected and the patient received trimethoprim-sulfamethoxazole and recovered.

Infectious disease colleagues from all over the world trained in microscopy, if queried, could cite many similar examples where our skills at the bedside and with the microscope made the difference in the survival of a sick patient. It is time we demanded the recognition that a thorough history, a meticulous physical examination, and microscopic analysis are our "stock-in-trade" and that they are critical to the practice of clinical microbiology and infectious disease. We must continually strive to develop these skills and pass them on 
to the next generation of practitioners of our beloved specialty. If we fail in this endeavor, Dr. House and his ilk will take our places. They will always be in a hurry; they will deal with patients very cavalierly and superficially; they will do little critical thinking; and many of their patients will die without a diagnosis. They will drive up the cost of health care by treating culture results rather than patients; and, sadly, they will burn out because their brand of medicine is neither challenging nor satisfying. However, if we are successful in passing on our timeless practice style to these bright and idealistic young men and women, we will have given anonymous gifts to them and to thousands of patients we will never meet. 